\title{
Challenges in psychiatric practice - the deaf patient and communication compromise
}

\author{
Jesus, Bianca Raquel ${ }^{1}$; Ramos, Sara ${ }^{1}$; Correia, João Martins ${ }^{1}$, Nunes, Susana Cristina ${ }^{1}$; Caetano, Ana Sofia ${ }^{1}$ \\ ${ }^{1}$ Unidade Local de Saúde da Guarda- E.P.E., Department of Psychiatry and Mental Health, Guarda, Portugal.
}

\section{Objectives}

To discuss the relationship between hearing impairment $(\mathrm{HI})$ and psychosis and the challenges in the diagnosis and management of deaf people (DP).

\section{Background and aims}

It has been reported that $20-54 \%$ of people with $\mathrm{HI}$ present psychotic disorders.(1) Considering the challenges in communication, the clinical assessment of these patients, namely the psychiatric evaluation, is demanding.

\section{Materials and methods}

Presentation of a clinical vignette and non-systematic review of literature featured in the PubMed database.

\section{Case report}

We present the case of a 45-year-old man (Mr.P.). He lived in the countryside with his wife and daughters. He was currently unemployed. Mr.P. had pre-lingual deafness, had had adapted teaching methods and concluded the basic education. He had no other health problem.

He was brought to a psychiatric consultation by his family, with complaints of altered behavior - the patient had quit his job, became aggressive and stopped paying the bills - and soliloquies in sign language.

The hearing impairment prevented appropriate history being taken directly from the patient, so his daughter provided the information and assisted with translation. Upon further investigation, the patient was found to believe that a conspiracy within his family-in-law was preventing him from becoming a very rich man. His suspicions had escalated to a point which compromised his marriage.

The mental health examination found Mr.P. very tense, with delirious mood and soliloquies suggesting hallucinatory activity and persecutory delusions concerning his wife's family. He lacked insight into his illness.

Based on the history and mental status examination, Mr.P was diagnosed with a psychotic disorder.

\section{Results}

Kraepelin (1915) was the first to describe the presence of paranoia and persecutory delusions in patients with impaired hearing.(2)(3)

The decoding of speech is an active central auditory process based on prior exposure and learning of what are meaningful sounds during the early life stages critical to language development.(4)

Linszen et al, in a meta-analyses confirm an association between $\mathrm{HI}$ and psychosis.(3) The presence of $\mathrm{HI}$ is associated with a significantly increased risk of hallucinations and delusions in the general adult population.(3) Studies suggest that DI are more likely to present with developmental, mood, impulse control, or personality disorders.(5) Several hypothesis have been proposed to explain the increased prevalence of psychosis in people with $\mathrm{HI}$. Linszen et al. sorted the various explanatory hypotheses according to their functional domain: interpersonal, cognitive and neurobiological.(3)

In this particular case, we observed the difficulties in history collection and psychiatric assessment. DP present significant challenges in the clinical practice: not only do they have their own language; they possess a specific cultural and linguistic identity. Additionally, their disability may impact behavior patterns, cognition and social skills as well as increase the risk of mood, impulse or personality disorders.

Most psychiatrists lack familiarity with DP cultural norms and specificities and do not have training in sign language (SL), which remains a barrier to communication and to effective diagnosis. The necessity of adding an SL interpreter to facilitate communication, can often introduce additional subjectivity.(6)

\section{Conclusions}

This case report demonstrates the challenges faced in the clinical and mental health setting when treating DP.

Most mental health professionals are not trained in sign language, and therefore require the support of written communication, or the presence of a family member or translator, which raises ethical concerns.

Strategies to facilitate the evaluation and management of mentally ill DP are needed, which may include specialized centers or availability of translators or sign language courses for health professionals.

\section{References}

1. Aleixo MA, Moreira CA, Sobreira G, et.al Auditory hallucinations in a deaf patient? - A clinical report. Eur Psychiatry. 2016;33:S527. 2. Cooper AF. Deafness and psychiatric illness. Br J Psychiatry.1976 Sep 1;129(3):216-26. 3. Linszen MMJ, Brouwer RM, Heringa SM, Sommer IE. Increased risk of psychosis in patients with hearing impairment: Review and meta-analyses. Neurosci Biobehav Rev. 2016;62:1-20. 4.Paijmans R, Cromwell J, Austen S. Do profoundly prelingually deaf patients with psychosis really hear voices? Am Ann Deaf. 2006;151(1):42-8. 5. Weiler C, Landsberger SA, Diaz DR. Differential diagnosis of psychosis in a deaf inpatient with language dysfluency: A case report. Clin Schizophr Relat Psychoses. 2013;7(1):42-5. 6. Landsberger SA, Diaz DR. Identifying and assessing psychosis in deaf psychiatric patients. Curr Psychiatry Rep. 2011;13(3):198-202. 